\title{
Perioperative blood lactate levels, pyruvate levels, and lactate-pyruvate ratio in children undergoing cardiopulmonary bypass for congenital heart disease
}

\author{
Santosh Shinde, ${ }^{1}$ Kumud Golam, ${ }^{2}$ Pawan Kumar, ${ }^{3}$ Neela Patil, ${ }^{1}$ Keshavan Sadacharan ${ }^{2}$
}

\begin{abstract}
인
Background: Cardiopulmonary bypass (CPB) affects almost every body system by hypoperfusion either subclinically or clinically and produces a systemic inflammatory response owing to contact of blood with mechanical surfaces. There has been no documentation regarding pyruvate in predicting postoperative mortality and morbidity. Aim: This study was carried out to evaluate lactate levels, pyruvate levels, and lactate-pyruvate ratio in pediatric patients undergoing CPB (for correction of congenital cardiac anomaly) and their correlation to perioperative outcomes. Method: 50 consecutive patients (less than 14 years of age) of various congenital heart diseases undergoing CPB were studied. Patients were classified into three categories according to their surgical complexity. Arterial blood samples were collected at different stages of CPB to estimate blood lactate and pyruvate levels by using documented spectrophotometric method. Results: The observed mean baseline lactate levels were $2.24 \pm 0.79 \mathrm{mmol} / \mathrm{l}$ (normal range of $0.9-1.7$ $\mathrm{mmol} / \mathrm{l})$. The mean circulating lactate levels, at 15 and $45 \mathrm{~min}$ after institution of CPB, increased to $4.49_{ \pm} 1.2$ and $5.24 \pm 1.02 \mathrm{mmol} / \mathrm{l}$, respectively. A progressive decline in the mean lactate levels was noted during rewarming $\left(\right.$ at $35^{\circ} \mathrm{C}$ ) and immediately off-bypass which continued steadily even 24 and $48 \mathrm{~h}$ postoperatively. The mean baseline lactate-pyruvate ratio was 24.73 , which increased at 15 and $45 \mathrm{~min}$ after institution of $\mathrm{CPB}$, rewarming (at $35^{\circ} \mathrm{C}$ ), and immediately off-bypass. As far as the duration of CPB is concerned, we found that lactate levels were elevated significantly $(P<0.05)$ and the lactate-pyruvate ratio was significantly high $(P<0.001)$ during rewarming, off-bypass, and 24- and 48-h post-CPB in patients requiring CPB for more than $1 \mathrm{~h}$. The average duration of postoperative mechanical ventilation, inotropic support, and lactate-pyruvate ratio were significantly higher $(P<0.001)$ in category III of patients in comparisons with categories I and II. Conclusion: In patients undergoing CPB for congenital heart operation, elevations in lactate-pyruvate ratio can predict the postoperative outcome significantly better in comparison with lactate levels.
\end{abstract}

Key Words: Cardiopulmonary bypass, Congenital heart disease, Lactate-pyruvate ratio, Lactic acidosis

\section{Introduction}

Cardiopulmonary bypass (CPB) is established during

\section{From:}

'Department of Biochemistry, L.T.M. Medical College and General Hospital, Sion, Mumbai, ${ }^{2}$ Department of Anesthesiology, L.T.M. Medical College and General Hospital, Sion, Mumbai, ${ }^{3}$ Department of Cardiovascular Thoracic Surgery, L.T.M. Medical College and General Hospital, Sion, Mumbai, India

\section{Correspondence:}

Santosh B. Shinde, 9-Dhanshri CHS, Nanda Patakar Road, Vile-Parle (East), Mumbai-400057, India. E-mail: santosh234@rediffmail.com various cardiac operations to allow adequate systemic oxygenation and perfusion during the surgical procedure..$^{[1]} \mathrm{CPB}$, being a nonphysiological condition, affects almost every body system secondary to hypoperfusion, either subclinically or clinically, and also produces a systemic inflammatory response owing to contact of blood with mechanical surfaces. Much attention has been focused in recent years on the adverse effects of CPB,

\section{Free full text available from www.ijccm.org}


particularly in pediatric patients undergoing surgical repair. Evidence presented has shown significant activation of various inflammatory mediators, including components of the complement cascade, and activation of neutrophils and platelets resulting in local and systemic production of circulating proinflammatory cytokines and adhesion molecules.

Tissue perfusion is at risk during cardiac surgery and in the immediate postoperative period. ${ }^{[2]}$ The development of predictors of death involves evaluating multiple different cardiorespiratory physiologic indexes. ${ }^{[2]}$ This approach is often difficult in infants with congenital heart disease (CHD) because of their small size, which limits invasive monitoring capabilities and reliable diagnostic options. Despite these obstacles, the search for predictors to help direct aggressive interventions in this patient population remains an important goal.

It is a well-known fact that tissue hypoperfusion is associated with lactic acidosis owing to anaerobic metabolism. Measurement of blood lactate levels can hence be used as a marker to assess the adequacy of tissue perfusion. ${ }^{[3]}$ There are no studies evaluating the use of pyruvate and lactate-pyruvate ratio as a marker for assessing tissue perfusion. Hence, measuring perioperative blood lactate levels, pyruvate levels, and lactate-pyruvate ratio, during CPB for congenital cardiac diseases, may provide a diagnostic and prognostic tool.

The aim of the study was to establish the relationship of lactate levels, pyruvate levels, and lactate-pyruvate ratios in patients undergoing CPB for correction of congenital cardiac anomaly and their correlation to perioperative outcome, morbidity, and mortality.

\section{Material and Methods}

Fifty consecutive patients undergoing CPB for CHD were included in this study. All were elective procedures. The institutional ethics committee gave approval and an informed consent was obtained from every patient. Based on the surgical complexity, Jenkins and colleagues allocated the patients into categories as described. ${ }^{[2]}$

Category I: Atrial septal defect (ASD).

Category II: Ventricular septal defect (VSD), atrioventricular canal, subaortic stenosis, open pulmonary valvotomy.

Category III:Tetralogy of Fallot (TOF), total anomalous pulmonary venous connection, truncus arteriosus, aortopulmonary window.

\section{Anesthesia Technique}

All were premedicated with injection morphine $(0.2 \mathrm{mg} /$ $\mathrm{kg}$ ) and promethazine $(0.5 \mathrm{mg} / \mathrm{kg})$ intramuscularly approx 30 min prior to induction of anesthesia. Anesthesia was induced with injection of thiopentone $(5 \mathrm{mg} / \mathrm{kg})$, followed by assisted ventilation with a mixture of $50 \%$ oxygen $\left(\mathrm{O}_{2}\right)$ and $50 \%$ nitrous oxide $\left(\mathrm{N}_{2} \mathrm{O}\right)$, followed by injection of vecuronium $(0.1 \mathrm{mg} / \mathrm{kg})$. Ryles tube and nasopharyngeal probes were inserted and then endotracheal intubation, using an appropriate sized portex tube, was carried out. Anesthesia was maintained with a mixture of $50 \% \mathrm{O}_{2}, 50 \% \mathrm{~N}_{2} \mathrm{O}$, halothane $(0.5-1 \%)$, and 5-10 mg/ $\mathrm{kg} / \mathrm{h}$ I.V fentanyl.

Morphine $(0.05 \mathrm{mg} / \mathrm{kg})$ was administered before incision and $0.15 \mathrm{mg} / \mathrm{kg}$ was added to the priming solution. The bypass circuit was primed with a mixture of ringer lactate and plasma. If required, blood was added to the prime to maintain a circulating hematocrit of $25-30 \%$.

CPB was instituted after systemic heparinization (using $3000 \mathrm{IU} / \mathrm{kg}$ of porcine lung heparin) and cardioplegia was administered (using cold hyperkalemic blood containing solution) via the aortic root after the application of aortic cross-clamp. Nasopharyngeal temperature was decreased during CPB. The flow rate of 2.4 multiplied by body surface area (in $1 / \mathrm{min} / \mathrm{m}^{2}$ ) was maintained at $32^{\circ} \mathrm{C}$. The mean arterial pressure was maintained between 60 and $65 \mathrm{mmHg}$ through an invasive arterial line. Urine output was monitored throughout the procedure. Blood sugar was monitored using a glucometer intraoperatively and the sugar levels were maintained between 180 and $240 \mathrm{mg} \%$. Anesthesia on bypass was maintained with a fentanyl drip. During rewarming, 0.1 $\mathrm{mg} / \mathrm{kg}$ morphine and $0.1 \mathrm{mg} / \mathrm{kg}$ vecuronium were added to the reservoir. CPB was discontinued and heparin was neutralized with protamine. Patients received inotropic support, if required. The inotrope of choice was dobutamine $(5-10 \mathrm{ig} / \mathrm{kg} / \mathrm{min})$ followed by adrenaline $(0.06-0.6 \mathrm{ig} / \mathrm{kg})$. Post-CPB anesthesia was maintained using $50 \% \mathrm{O}_{2}, 50 \% \mathrm{~N}_{2} \mathrm{O}, 0.5-1 \%$ halothane, and vecuronium (1/4th of induction dose) as and when needed. Before shifting the patient to cardiac intensive 
care unit, $0.1 \mathrm{mg} / \mathrm{kg}$ morphine was given intravenously. In the intensive care unit the patients were electively ventilated, whereas continuous monitoring of hemodynamic parameters and arterial blood gas analysis was followed.

Blood lactate and pyruvate level measurement: For measuring lactate and pyruvate levels, arterial blood was collected through the intra-arterial catheter (inserted for blood pressure monitoring) immediately after induction of anesthesia. This was termed as the baseline sample. Subsequent samples were collected at $15 \mathrm{~min}$ after institution of CPB, 45 min after institution of CPB (if any), rewarming (at $\left.35^{\circ} \mathrm{C}\right)$, immediately after cessation of $\mathrm{CPB}$, and $24-$ and 48 -h postsurgery.

The blood samples were collected in a sample tube containing $3 \mathrm{ml}$ of $5 \%$ metaphosphoric acid. Samples were stored in ice carriers and transferred to the laboratory where they were immediately centrifuged. The protein-free filtrate was then collected in another tube for the estimation of lactate and pyruvate (using the spectrophotometric method at $340 \mathrm{~nm})_{.}^{[4]}$

The endpoint of the study was predetermined, with the last sample being collected at $48 \mathrm{~h}$ after termination of $\mathrm{CPB}$. The one-way ANOVA was used for statistical analysis.

\section{Results}

The average age was $6.3 \pm 4.1$ years with a weight of $15.1 \pm 7.6 \mathrm{~kg}$. There are 39 males and 11 females. There was one mortality. Table 1 shows the distribution of the patients according to the surgical complexity. Maximum patients (25; i.e.,. $50 \%$ of the patients) belonged to category II. The distributions of individual surgical procedures are shown in Table 2. Most patients underwent a VSD closure.

Mean lactate level, pyruvate level, and lactate-pyruvate ratio in various categories of patients are shown in Table 3. No statistically significant difference in the elevation in lactate and pyruvate levels ( $\mathrm{mmol} / \mathrm{l})$ and lactate-pyruvate ratio (during $\mathrm{CPB}$ ) in various categories was seen.

Comparison of the duration of CPB vs changes in perioperative lactate and pyruvate levels and lactatepyruvate ratio are shown in Table 4. Lactate levels were elevated significantly $(P<0.05)$ and lactate-pyruvate ratio was significantly high $(P<0.001)$ during rewarming, offbypass, and 24- and 48-h post-CPB in patients requir-

\begin{tabular}{|c|c|c|}
\hline Category & No. of patients & Percentage \\
\hline 1 & 10 & 20 \\
\hline II & 25 & 50 \\
\hline III & 15 & 30 \\
\hline
\end{tabular}

Table 2: Types of surgery

\begin{tabular}{lc}
\hline Type of surgery & No. of Patients \\
ASD closure & 10 \\
VSD closure & 23 \\
TOF repair & 14 \\
A-V canal closure & 2 \\
TGV correction & 1 \\
\hline
\end{tabular}

\begin{tabular}{|c|c|c|c|c|c|c|c|c|c|}
\hline \multirow[t]{2}{*}{ Category } & \multicolumn{3}{|c|}{ Baseline } & \multicolumn{3}{|c|}{$15 \mathrm{~min}$} & \multicolumn{3}{|c|}{$45 \mathrm{~min}$} \\
\hline & $\mathbf{L}$ & $\mathbf{P}$ & L/P & $\mathbf{L}$ & $\mathbf{P}$ & $L / P$ & $\mathbf{L}$ & $\mathbf{P}$ & L/P \\
\hline I & $2.08 \pm 0.98$ & $0.09 \pm 0.001$ & $23.1 \pm 10.9$ & $4.7 \pm 0.8$ & $0.11 \pm 0.02$ & $43.1 \pm 8.03$ & $5.1 \pm 1.8$ & $0.2 \pm 0.01$ & $31.3 \pm 13.2$ \\
\hline II & $2.2 \pm 0.83$ & $0.12 \pm 0.02$ & $24.4 \pm 10.7$ & $4.2 \pm 1.3$ & $0.1 \pm 0.02$ & $42.6 \pm 15.6$ & $5.15 \pm 1.5$ & $0.19 \pm 0.01$ & $32.4 \pm 11.2$ \\
\hline III & $2.2 \pm 0.59$ & $0.09 \pm 0.005$ & $26.2 \pm 7.7$ & $4.6 \pm 1.2$ & $0.1 \pm 0.01$ & $46.3 \pm 14.2$ & $5.2 \pm 1.4$ & $0.19 \pm 0.01$ & $31.7 \pm 8.6$ \\
\hline Significance & NS & NS & NS & NS & NS & NS & NS & NS & NS \\
\hline
\end{tabular}

L, Lactate; P, pyruvate; L/P, lactate-pyruvate ratio; values expressed as mean \pm SD; NS, non significant (multiple comparison by using one-way ANOvA).

Table 3: Mean lactate level, pyruvate level ( $\mathrm{mmol} / \mathrm{l})$, and lactate-pyruvate ratio in various categories of patients (continued)

\begin{tabular}{|c|c|c|c|c|c|c|c|c|c|c|c|}
\hline \multicolumn{3}{|c|}{ Rewarming } & \multicolumn{3}{|c|}{ Off-bypass } & \multicolumn{3}{|c|}{$24 \mathrm{~h}$} & \multicolumn{3}{|c|}{$48 \mathrm{~h}$} \\
\hline L & $\mathbf{P}$ & L/P & L & $\mathbf{P}$ & L/P & L & $\mathbf{P}$ & L/P & L & $\mathbf{P}$ & L/P \\
\hline $6.9 \pm 1.9$ & $0.29 \pm 0.01$ & $14.6 \pm 3.67$ & $6.4 \pm 1.9$ & $0.33 \pm 0.01$ & $15.3 \pm 1.3$ & $4.0 \pm 1.4$ & $0.19 \pm 0.01$ & $15.8 \pm 2.3$ & $2.8 \pm 0.74$ & $0.1 \pm 0.01$ & $26.7 \pm 1.6$ \\
\hline $7.7 \pm 3.1$ & $0.3 \pm 0.02$ & $13.0 \pm 4.6$ & $6.3 \pm 3.5$ & $0.33 \pm 0.02$ & $12.4 \pm 5.0$ & $4.4 \pm 2.5$ & $0.19 \pm 0.02$ & $15.3 \pm 6.6$ & $3.1 \pm 1.5$ & $0.1 \pm 0.01$ & $25.4 \pm 10$ \\
\hline $8.0 \pm 3.0$ & $\begin{array}{l}0.29 \pm 0.02 \\
\text { NS }\end{array}$ & $\begin{array}{l}11.3 \pm 4.5 \\
\text { NS }\end{array}$ & $\begin{array}{l}6.3 \pm 2.7 \\
\text { NS }\end{array}$ & $\begin{array}{l}0.33 \pm 0.02 \\
\text { NS }\end{array}$ & $\begin{array}{l}10.8 \pm 3.6 \\
N S\end{array}$ & $\begin{array}{l}5.1 \pm 2.7 \\
\text { NS }\end{array}$ & $\begin{array}{l}0.19 \pm 0.02 \\
\text { NS }\end{array}$ & $\begin{array}{l}15.3 \pm 6.5 \\
\text { NS }\end{array}$ & $\begin{array}{l}3.4 \pm 1.8 \\
\text { NS }\end{array}$ & $\begin{array}{l}0.1 \pm 0.02 \\
\text { NS }\end{array}$ & $\begin{array}{l}26.4 \pm 8.3 \\
\text { NSNS }\end{array}$ \\
\hline
\end{tabular}

L, Lactate; P, pyruvate; L/P, lactate-pyruvate ratio; values expressed as mean \pm SD; NS, non significant (multiple comparison by using one-way ANova). 
Table 4: Comparison of duration of CPB and change in perioperative lactate level (mmol/l), pyruvate level (mmol/l), and lactate-pyruvate ratio

\begin{tabular}{|c|c|c|c|c|c|c|c|c|c|}
\hline \multirow[t]{2}{*}{ Duration of CPB } & \multicolumn{3}{|c|}{ Baseline } & \multicolumn{3}{|c|}{$15 \mathrm{~min}$} & \multicolumn{3}{|c|}{$45 \mathrm{~min}$} \\
\hline & $\mathbf{L}$ & $\mathbf{P}$ & L/P & L & $\mathbf{P}$ & L/P & L & $\mathbf{P}$ & L/P \\
\hline$<1 \mathrm{~h}$ & $2.42 \pm 0.87$ & $0.1 \pm 0.02$ & $24.2 \pm 9.98$ & $4.6 \pm 1.27$ & $0.12 \pm 0.07$ & $38.3 \pm 16.5$ & $5.9 \pm 1.7$ & $0.12 \pm 0.09$ & $49 \pm 16$ \\
\hline $1-2 \mathrm{~h}$ & $2.04 \pm 0.63$ & $0.09 \pm 0.02$ & $22.7 \pm 8.5$ & $4.2 \pm 1.15$ & $0.11 \pm 0.06$ & $38.1 \pm 16.2$ & $6.3 \pm 2.3$ & $0.12 \pm 0.04$ & $52 \pm 13$ \\
\hline Significance & NS & NS & NS & NS & NS & NS & NS & NS & NS \\
\hline
\end{tabular}

$\mathrm{L}$, lactate; $\mathrm{P}$ : pyruvate; $\mathrm{L} / \mathrm{P}$, lactate/pyruvate ratio; values expressed as mean $\pm \mathrm{SD}$.

${ }^{*} P<0.05$ as compared with $<1 \mathrm{~h}$ duration of CPB.

${ }^{* *} P<0.001$ as compared with $<1 \mathrm{~h}$ of $\mathrm{CPB}$.

Table 4: Comparison of duration of CPB and change in perioperative lactate level (mmol/l), pyruvate level (mmol/l), and lactate-pyruvate ratio (continued)

\begin{tabular}{|c|c|c|c|c|c|c|c|c|c|c|c|}
\hline \multicolumn{3}{|c|}{ Rewarming } & \multicolumn{3}{|c|}{ Off-bypass } & \multicolumn{3}{|c|}{$24 \mathrm{~h}$} & \multicolumn{3}{|c|}{$48 \mathrm{~h}$} \\
\hline L & $\mathbf{P}$ & L/P & $\mathbf{L}$ & $\mathbf{P}$ & L/P & $\mathbf{L}$ & $\mathbf{P}$ & L/P & $\mathbf{L}$ & $\mathbf{P}$ & L/P \\
\hline $7.2 \pm 2.6$ & $0.20 \pm 0.07$ & $36 \pm 9.3$ & $5.7 \pm 1.8$ & $0.15 \pm 0.08$ & $38 \pm 16$ & $3.8 \pm 1.1$ & $0.2 \pm 0.09$ & $20 \pm 6.4$ & $2.8 \pm 1.0$ & $0.1 \pm 0.03$ & $28.3 \pm 10.2$ \\
\hline $8.2 \pm 3.4$ & $0.30 \pm 0.1$ & $27 \pm 12$ & $7.1 \pm 3.8$ & $0.40 \pm 0.13$ & $18 \pm 10$ & $5.3 \pm 2.9$ & $0.18 \pm 0.07$ & $29 \pm 11$ & $3.9 \pm 2.1$ & $0.1 \pm 0.02$ & $45.1 \pm 20.2$ \\
\hline * & * & $* *$ & * & NS & ** & * & NS & ** & * & NS & $* *$ \\
\hline
\end{tabular}

$\mathrm{L}$, lactate; P: pyruvate; L/P, lactate/pyruvate ratio; values expressed as mean $\pm \mathrm{SD}$.

${ }^{*} P<0.05$ as compared with $<1 \mathrm{~h}$ duration of CPB.

${ }^{* *} P<0.001$ as compared with $<1 \mathrm{~h}$ of CPB.

ing CPB for more than $1 \mathrm{~h}$. Pyruvate was significantly elevated during rewarming in patients requiring CPB for more than $1 \mathrm{~h}$. The rise in lactate or pyruvate levels was more significant in comparison with absolute lactate or pyruvate levels.

Table 5 shows a comparison of the various surgical categories with mean duration of postoperative inotropic and mechanical support and the associated elevations in lactate and pyruvate levels. The average durations of postoperative mechanical ventilation, inotropic support, and lactate-pyruvate ratio were significantly higher $(P<$ 0.001 ) in category-III patients in comparison with categories I and II. Lactate was less significant $(P<0.05)$ in category III.

\section{Discussion}

Advances in pediatric cardiac surgery for complex CHDs continue. It is essential to identify patients who

Table 5: Comparison in various surgical categories of lactate level and lactate-pyruvate ratio, with mean duration of postoperative ionotropic and mechanical support

\begin{tabular}{lllll}
\hline Categories & $\begin{array}{l}\text { Lactate } \\
(\mathbf{m m o l} / \mathrm{l})\end{array}$ & $\begin{array}{l}\text { Lactate/ } \\
\text { pyruvate } \\
\text { ratio }\end{array}$ & $\begin{array}{l}\text { lonotropic } \\
\text { support }(\mathbf{h})\end{array}$ & $\begin{array}{l}\text { Mechanical } \\
\text { support }(\mathbf{h})\end{array}$ \\
I & $4.5 \pm 0.98$ & $19.2 \pm 8.8$ & $9.8 \pm 3.1$ & $10.6 \pm 2.6$ \\
II & $4.6 \pm 1.0$ & $17.7 \pm 9.8$ & $15.8 \pm 9.0$ & $17.08 \pm 7.58$ \\
III & $5.0 \pm 1.1^{* *}$ & $27.8 \pm 10.5^{*}$ & $28 \pm 9.7^{*}$ & $18.67 \pm 9.2^{*}$ \\
\hline & & \\
Values expressed as mean $\pm S D$. \\
${ }^{*} P<0.001$ as compared with categories I and II. \\
${ }^{* *} P<0.05$ as compared with categories I and II.
\end{tabular}

have an increased risk for postoperative morbidity and mortality and may benefit from early aggressive intervention. A small but substantial number of patients with complex CHD continue to die in the immediate postoperative period. ${ }^{[5]}$ Lactate is a marker of anaerobic metabolism and tissue oxygen deficit. The severity of lactic acidosis in critically ill patients correlates with overall oxygen debt and survival. ${ }^{[6]}$ As lactate concentration increased from 2 to $8 \mathrm{mmol} / \mathrm{l}$, the estimated probability of survival decreased from $90 \%$ to $10 \% .{ }^{[7]}$

Increases in tissue lactate concentration and acidosis correlate with depletion of high-energy phosphate compounds and with cellular dysfunction. Because lactic acid is a product of anaerobic metabolism, elevated lactate levels represent inadequate tissue oxygen delivery. This decrease in oxygen delivery represents a combination of tissue hypoperfusion and hypoxemia, prompting a systematic diagnostic evaluation. Several studies have shown a strong correlation between blood lactate levels and the risk of morbidity and mortality in varying clinical situations such as circulatory shock, septic shock, severe hypoxemia, liver failure, diabetes mellitus, and others. ${ }^{[6,8-10]}$ To the best of our knowledge, no study has been undertaken to evaluate pyruvate in predicting postoperative mortality and morbidity. When tissue hypoxia is present, pyruvate oxidation in the Krebs cycle is decreased. Lactate production is increased and ATP formation continues via glycolysis. Hence in this study, instead of measuring only lactate levels we decided to 
also measure pyruvate levels in predicting the postoperative outcomes.

In adults most of the studies compared the preoperative clinical condition according to the New York Heart Association (NYHA) classification to the changes in lactate levels during CPB. ${ }^{[11]}$ However, in children NYHA classification is not applicable. Therefore, we decided to categorize the patients according to the complexity of surgery. ${ }^{[2]}$ In our study of 50 patients, $10(20 \%$ of the patients) belonged to category I, 25 (50\% of the patients) to category II, and 15 (30\% of the patients) to category III.

An early recognition of patients at risk for the development of hyperlactemia may allow intervention in a timely manner, hence reducing the postoperative morbidity. Potential interventions that may alter organ perfusion and tissue oxygenation during CPB include the following:(1) manipulation of perfusion pressure and flow rates, (2) levels of hypothermia and duration of cooling and rewarming, (3) alteration in the circuit prime to ensure optimal hematocrit value and oncotic pressure, (4) the use of agents to specifically modify the systemic inflammatory response, and (5) optimal institution of ionotropes and vasodilators.

In our study, the mean baseline lactate level was 2.24 $\pm 0.79 \mathrm{mmol} / \mathrm{l}$ and the level increased 15 and $45 \mathrm{~min}$ after institution of CPB to $4.49 \pm 1.2$ and $5.24 \pm 1.02 \mathrm{mmol} /$ I, respectively. As contrary to other studies,,$^{[2,5]}$ lactate levels remained high during rewarming and off-bypass. Thereafter, the levels began to decline 24- and 48-h postoperatively with mean values of $4.5 \pm 1.3$ and $3.36 \pm 1.72 \mathrm{mmol} / \mathrm{l}$, respectively. We found no significant difference in elevations of lactate levels between various surgeries. Even when the lactate levels exceeded in the study by Munoz et al., ${ }^{[2]}$ there was no significant change in the postoperative outcomes.

The mean baseline lactate-pyruvate ratio was 24.73 , which increased during CPB. Thereafter, that ratio began to decline during rewarming and off-bypass to 26.2 and 19.3, respectively. The lactate-pyruvate ratio remained elevated even after $24 \mathrm{~h}$ and $48 \mathrm{~h}$ in those who had postoperative morbidity and mortality. Out of 50 patients, one patient expired. It was a case of VSD with very high $\mathrm{pH}$. In this patient the lactate-pyruvate ratio at
$48 \mathrm{~h}$ was 88.67.

We compared the mean lactate levels and lactate-pyruvate ratio perioperatively with the duration of $\mathrm{CPB}$. $\mathrm{Pa}$ tients were distributed into two groups, those with bypass duration of less than $1 \mathrm{~h}$ and the others with duration of more than $1 \mathrm{~h}$. We found that elevation in lactate levels and lactate-pyruvate ratio were significantly higher in the group in which the duration of CPB exceeded $1 \mathrm{~h}$. This is similar to the study done by Munoz et al. who analyzed the duration of CPB and circulatory arrest with a change in lactate levels. However, the elevations in lactate-pyruvate ratio were more significant than elevation in absolute lactate level values.

The relationship between lactate level, pyruvate level, and the different categories of patients and duration of postoperative inotropic support and ventilation was studied. The average duration of postoperative mechanical ventilation, inotropic support, and lactate-pyruvate ratio were significantly higher $(P<0.001)$ in category III of patients in comparison with categories I and II. Lactate was less significant $(P<0.05)$ in category III.

Hence, we found that lactate-pyruvate ratio is more valuable in CHD patients undergoing corrective surgery with $\mathrm{CPB}$ as compared with lactate levels alone.

\section{Conclusion}

We conclude that in patients undergoing CPB for congenital heart operation, lactate-pyruvate ratio has a good predictive value for postoperative outcome as compared with lactate level.

\section{References}

1. Shinde S, Golam K, Kumar P, Patil N. Blood lactate levels during cardiopulmonary bypass for valvular heart surgery. Annals Cardiac Anaesthesia 2005;8:39-44.

2. Munoz R, Laussen PC, Palacio G, Zienko L, Piercey G, Wessel DL. Changes in whole blood lactate levels during CPB for surgery for congenital cardiac disease: an early indicator of morbidity and mortality. J Thorac Cardiovasc Surg 2000;119:15562.

3. Hue L, Rider MH. Role of fructose 2,6-biphosphate in the control of glycolysis in mammalian tissues. Biochem J 1987;245:31324.

4. MarbachEP,Weil MH. Rapid enzymatic measurement of blood lactate and pyruvate. Clinical chemistry 1967;13:314-25. 
5. Cheifetz IM, Frank HK, Schulman RS, Greeley WJ, Ungerleider RM, Meliones JN. Serum lactates correlate with mortality after operation for complex congenital heart disease. Ann Thorac Surg 1997;64:735-8.

6. Mizock BA, Falk JL. Lactic acidosis in critical illness. Crit Care Med 1992;20:80-93.

7. Weil MH, Afifi AA. Experimental and clinical studies on lactate and pyruvate as indicators of the severity of acute circulatory failure. Circulation 1970;41:989-1001.
8. Broder G, Weil NH. Excess lactate an index of reversibility of shock in human patients. Science 1964;143:1457-9.

9. Vitek V, Cowley RA. Blood lactate in prognosis of various forms of shock. Ann Surg 1971;173:308-13.

10. Waxman K, Nolan LS, Shoemaker WC. Sequential perioperative lactate determination. Crit Care Med 1982;10:96-9.

11. Demer SP, Eikouris, Martineau R. Outcome with high blood lactate levels during cardiopulmonary bypass in adult cardiac operation. Ann Thorac Surg 2000;70:2082-6. 